\title{
La OMC y la privatización de los servicios culturales
}

La Organización Mundial del Comercio (www. wto.org) es una agrupación de países creada fuera del ámbito de influencia de la ONU, con el objetivo de regir el comercio internacional. Nace en 1995 como resultado de las negociaciones de la Ronda de Uruguay (1986-1994).

Su misión consiste en facilitar a las empresas productoras de bienes y servicios y a los exportadores e importadores el desarrollo de su actividad comercial internacional, removiendo los obstáculos internos de los países miembros. La OMC desempeña las siguientes funciones para el comercio internacional: sirve de foro para negociaciones y acuerdos comerciales entre los Estados miembros; administra la ejecución de los acuerdos comerciales; trata de resolver las diferencias comerciales entre países y supervisa las políticas comerciales nacionales para que se ajusten al cumplimento de lo acordado.

Los pilares sobre los que descansa este sistema son los Acuerdos de la OMC, que han sido negociados y firmados por la mayoría de los países que participan en el comercio mundial.

\section{El Acuerdo General sobre el Comercio de Servicios (AGCS)}

El AGCS entró en vigor con la creación de la OMC en 1995, pero fue en enero de 2000, después de la cumbre de Seattle, cuando los miembros de la OMC iniciaron nuevas rondas de negociaciones para promover la liberalización progresiva de todos los servicios (sanidad, educación, turismo, etc.) para el comercio internacional ${ }^{1}$. La novedad de este Acuerdo no estriba en la liberalización y privatización de servicios (cosa que ya vienen haciendo muchos gobiernos europeos) sino en que otorga a este proceso un marco institucional, con compromisos formales que se aplican a todos los países de la OMC y a los que se subordinan las políticas nacionales y tratados internacionales existentes, sin fijar límites a la extensión y duración del proceso, hasta alcanzar la liberalización total y estableciendo unas normas que lo hacen irreversible en la práctica².

\section{Un proceso en marcha}

El proceso de liberalización del comercio de servicios que contempla el AGCS está en marcha con el siguiente calendario acordado en la reunión de Doha en noviembre de 2001:

> A finales de junio de 2002 cada país de la OMC presentó sus demandas especificas sobre qué servicios y en que paises deseaba una apertura para ser suministrados en libre competencia.

> El 30 de marzo de 2003 es la fecha prevista para que los países presenten las ofertas sobre qué servicios están dispuestos a liberalizar.

> A partir de entonces comenzarán una serie de negociaciones bilaterales con la aspiración de que el proceso finalice definitivamente en 2005.

Para España es la Unión Europea la que está ejerciendo una posición común de sus quince miembros en lo relativo a la liberalización de servicios y en el proceso llamado de demandasofertas del $\mathrm{AGCS}^{3}$.

\section{La cultura en el AGCS}

El sector cultural dentro del Acuerdo General sobre el Comercio de Servicios ${ }^{4}$ está contemplado en los denominados "Servicios de Comunicación" y los "Servicios de ocio, cultura y deporte". Dentro de los Servicios de Comunicación se incluyen los Servicios Audiovisuales, clasificados en:

> Servicios de producción y de distribución de películas y videos

> Servicios de proyección de película

> Servicios de radio y televisión

$>$ Servicios de transmisión de radio y televisión

$>$ Grabación de sonidos

En cuanto a los Servicios Recreativos, Culturales y Deportivos, abarcan:

$>$ Servicios de espectáculos (incluyendo servicios de teatro, orquesta y circo)

$>$ Servicios de agencias de noticias

$>$ Bibliotecas, archivos, museos y otros servicios culturales

$>$ Servicios deportivos y otros servicios recreativos.

\section{Peligro de desaparición de los servicios públicos}

La negociación del Acuerdo General sobre el Comercio de Servicios ha generado el rechazo, sobre todo, entre los grupos contrarios a la globalización neoliberal, preocupados por la entrega de los bienes comunes, ecológicos, económicos, sociales y culturales de los paises, en mano de empresas multinacionales. Estas organizaciones consideran que las medidas que se adopten afectarán, en primera instancia, a las pequeñas y medianas empresas proveedoras de servicios locales. El AGCS obliga a los países a otorgar acceso ilimitado al mercado a proveedores extranjeros de servicios sin tener en cuenta su impacto social y medioambiental. Los gobiernos no podrán adoptar políticas que benefi- 


\section{$016-017$ \\ Noticias y comentarios \\ PH42 - Febrero 2003}

cien el tejido empresarial local que, al no poder competir, desaparecerá paulatinamente en beneficio de las grandes corporaciones multinacionales. Éstas, con enormes capitales para la inversión y apoyadas en políticas nacionales de bajos salarios y desregulación laboral, se impondrán en todos los sectores de servicio en régimen de monopolio, sin mejorarlos ni abaratarlos ${ }^{5}$.

Pero donde se produce un rechazo radical al AGCS es con respecto a los servicios públicos o prestados por el sector público: sanidad, pensiones, educación, cultural, transporte, telecomunicaciones, suministro de energía, agua, gestión de residuos, medio ambiente, etc. El Acuerdo General sobre el Comercio de Servicios limita la capacidad de los gobiernos para ejercer políticas en favor del interés común. La administración local, autonómica y estatal podrían verse obligadas a eliminar todas aquellas acciones tendentes a una adecuada regulación y financiación de servicios esenciales. Al mismo tiempo las empresas extranjeras tendrian derecho de acceso ilimitado a contratos de servicios como la recogida de residuos, saneamiento, turismo, agua y cultura, a escala local o estatal.

Los servicios públicos se establecieron para satisfacer las necesidades de las personas, no para el comercio y el beneficio económico y no pueden regirse por criterios de rentabilidad sino de interés social. De acceso universal, mantenidos por una fiscalidad solidaria, representan uno de los derechos sociales más significativos alcanzados por la ciudadanía a lo largo de la historia y son indispensables para luchar contra las desigualdades sociales y territoriales. La provisión de los servicios públicos se desarrolla en base a las necesidades sociales básicas del ciudadano y no a su capacidad de pago según las leyes del mercado. Por su propia naturaleza de bien público no deben ser liberalizados ni privatizados.

El AGCS amenaza particularmente los servicios públicos de los paises en desarrollo: donde éstos son embrionarios, la competencia internacional los destruirá y donde todavía son inexistentes, se impedirá para siempre su creación, reforzando y perpetuando así la desigualdad y la pobreza. En resumen, la aceptación del AGCS supondría:

$>$ el dominio de los mercados por un pequeño número de compañías privadas

> la pérdida de control democrático de los servicios públicos

> la caída de los precios a expensas de la calidad

$>$ la reducción de la protección medioambiental

> la pérdida de servicios básicos y de puestos de trabajo.

\section{Falta de transparencia en la negociación}

La liberalización y apertura de los servicios públicos al comercio internacional es un tema es- pecialmente sensibles y de enormes consecuencias para nuestro futuro. Uno de los argumentos de los colectivos en contra la AGCS con más fuerza es que este proceso se está llevando a cabo por la Comisión Europea de espalda a los ciudadanos, rodeado del más absoluto secretismo y vulnerando los más elementales principios democráticos de información y participación en la toma de decisiones por parte de la sociedad civil y sus representantes ${ }^{6}$.

Los principales beneficiarios del Acuerdo General sobre el Comercio de Servicios son los proveedores corporativos de servicios, decididos a extender su alcance comercial global y a convertir los servicios públicos de todo el mundo en mercados privados. Los movimientos sociales acusan a la Unión Europea de impulsar decididamente el AGCS como el modo más idóneo para conseguir que las empresas multinacionales se apoderen de este sector de negocio tan codiciado. Las empresas multinacionales, a través de sus lobbies, tienen en la práctica una enorme, aunque a menudo invisible, presencia en todo lo relativo a la OMC. A través de estos poderosos grupos de presión las empresas trasnacionales han dictado prácticamente el orden del dia de las negociaciones AGCS. Las organizaciones ciudadanas contrarias a la liberalización lamentan que el mundo empresarial esté mucho mejor informados del proceso por la Comisión Europea que el resto de los componentes de la sociedad civil?.

Por todo ello, los grupos contrarios al AGCS y la liberalización de los servicios públicos, exigen una moratoria de las negociaciones mientras no se haya llevado a cabo una evaluación del impacto que supondrá las obligaciones contraídas por este Acuerdo sobre las leyes, políticas y programas nacionales en las áreas sociales, medioambientales y económicas de cada uno de los países miembros de la Unión Europea.

\section{La mercantilización de la cultura}

La Organización Mundial del Comercio parte de una concepción mercantil de la cultura. Más allá de las tradicionales visiones humanista y antropológica, para el Acuerdo General sobre el Comercio de Servicios la cultura es otro producto (película, libro, disco, etc.) o servicio más (biblioteca, museo, teatro, etc.) objeto de mercado. Es decir un sector económico y de negocio para ser producido y suministrado por lógica comercial.

El AGCS entiende la cultura como servicio de ocio y entretenimiento e impide que la intervención pública contrapese la lógica comercial y consumista. Las administraciones no podrán destinar presupuesto a prestar servicios ciudadanos sin entrar en conflicto con el AGCS. Toda política pública (estatal, autonómica o local) tendente a regular o proteger la producción y prestación de servicios culturales es susceptible 
de ser considerada hostil al comercio mundial entiéndase el suministrado por grandes corporaciones multinacionales- y por tanto reprochable. Los intereses generales que representan las politicas públicas quedan de este modo supeditados a los particulares de las empresas.

Las primeras voces contrarias al AGCS desde el ámbito de los servicios culturales han surgido de las bibliotecas. Las organizaciones profesionales internacionales como el IFLA ya han manifestado su preocupación por el futuro que para las bibliotecas puede representar el Acuerdo General sobre el Comercio de Servicios y el peligro de que las propias bibliotecas dejen de existir como servicios públicos ${ }^{8}$.

En este mismo sentido la Asamblea de las Regiones de Europa celebró el pasado 18 de octubre de 2002 una reunión de Ministros regionales Europeos de Cultura y Educación en Brixen/ Bressanone, y emitió una firme declaración a favor de la diversidad cultural y en contra del Acuerdo General sobre el Comercio de Servicios (véase resumen adjunto) ${ }^{9}$.

\section{Notas}

${ }^{1}$ El AGCS sólo contempla dos excepciones: Ios servicios suministrados al público en el ejercicio de las facultades gubernamentales (bancos centrales, policía, justicia y ejército) y en el sector del transporte aéreo, los derechos de tráfico y todos los servicios relacionados directamente con el ejercicio de los derechos de tráfico.

${ }^{2}$ Para mas información se puede leer el documento:

El AGCS-Realidad y Ficción, a consultar en

http://www.wto.org/spanish/tratop_s/serv_s/ gats_factfiction_s.htm

${ }^{3}$ En concreto la Dirección General 1, Comité 133, liderado por el Comisario Europeo para el Comercio Pascal Lamy (http://trade-info.cec.eu.int/europa/index_en.php)

${ }^{4}$ La lista completa de servicios que incluye el GATS se puede consultar en http://www.wto.org/english/tratop_e/ serv_e/mtn_gns_w_120_e.doc
${ }^{5}$ Las principales organizaciones que están Ilevando a cabo la campaña en contra el AGCS son: Corporate Europe Observatory (http://www.gatswatch.org); World Development Movement (http://www.wdm.org.uk/campaign/ GATS.htm); y la red ATTAC(http://www.attac.org).

En concreto puede encontrarse información de utilidad en Attac Sevilla, Madrid o Cataluña. Con motivo de la pasada Cumbre de Jefes de Estado de la Unión Europea celebrada en Sevilla, en junio de 2002, ATTAC elaboró una Declaración de los ATTAC Europa sobre el AGCS que puede consultarse en: http://www.local.attac.org/ sevilla/blog.php?archivo=0mc.rdf

${ }^{6}$ Los colectivos contrarios al AGCS enviaron una carta abiek ta al Comisario Europeo responsable de las negociaciones, Pascal Lamy, con fecha 7 de mayo de 2002, firmada por cerca de 100 organizaciones, denunciando, entre otras cosas, la falta de transparencia en las negociaciones. Pascal Lamy, contestó en julio de 2002 justificando esta forma reservada de actuar de la OMC, que se puede leer en español en http://europa.eu.int/comm/ trade/services/plreply_es.htm

${ }^{7}$ Los intereses empresariales están representados, entre otros, por los siguientes lobbies:

La Mesa Europea de Empresarios (http://www.ert.be); UNICE (http://www.unice.org); Foro Europeo de Servicios (http://www.esf.be); Coalición Estadounidense de Servicios http://www.uscsi.org

${ }^{8}$ El IFLA trata del AGCS en http://www.ifla.org/III/clm/ p1/wto-ifla.htm y la American Library Association en http://www.vcn.bc.ca/bcla-ip/globalization/alareswto.html. Ver también artículo de Fiona Hunt, The WTO and the Threat to Libraries, en Progressive Librarian http://libr.org/PL/18_Hunt.html

${ }^{9}$ La Declaración completa en varios idiomas puede consultarse en http://www.are-regions-europe.org/ COMMUN/A214a1.html\#Brixen.

También está disponible abundante documentación sobre el AGCS y una selección de webs de interés en http://www.are-regions-europe.org/COMMUN/ A214b8gats.html

Carlos Romero Moragas

Dpto. de Formación y Comunicación del IAPH
Resumen de la Declaración de Brixen/Bressanone sobre la Diversidad Cultural y el AGCS

Nosotros, los miembros de la Asamblea de las Regiones de Europa, representando las opiniones y los intereses de nuestros ciudadanos,

$>$ Estimamos que el Acuerdo General sobre el Comercio de Servicios (AGCS) afecta a los servicios públicos en los ámbitos de la educación, de la cultura y de los medios de comunicación

$>$ Estimamos que el AGCS perpetúa la tendencia a privilegiar la prioridad comercial en detrimento de la calidad democráticamente aceptada

$>$ Estamos preocupados por las implicaciones del AGCS, puesto que tenemos responsabilidades democráticas en calidad de proveedores de servicios públicos para la educación, la cultura y los medios de comunicación

$>$ Afirmamos que estos servicios deberian estar a disposición de nuestros ciudadanos sobre una base de igualdad social, de universalidad y de altos criterios
> Solicitamos que, en nuestra calidad de representantes democráticos de nuestros ciudadanos, estemos implicados en toda las negociaciones futuras del AGCS que afecten a la educación, a la cultura y a las cuestiones de los medios de comunicación, conforme al principio de subsidiariedad

$>$ Solicitamos un acuerdo internacional a favor de la protección de la educación, de la cultura y de los medios de comunicación, que incluya la dimensión regional

> Solicitamos que los servicios en materia de educación, de cultura y de medios de comunicación, apoyados por órganos democráticos, sean excluidos de los futuras desarrollos del AGCS

$>$ Instamos a todos los miembros de la ARE y a los responsables de otras Regiones europeas a ejercer presión sobre sus consejos, sus gobiernos y la UE para perseguir los objetivos de la Declaración de Brixen sobre la Diversidad Cultural y el AGCS. 